http://www.jfas.info

\title{
IDENTIFYING NATIONAL SECURITY FUNDAMENTALS IN THE BIG DATA OF DIGITAL ASYMMETRICAL ENVIRONMENT COMMUNICATION
}

\author{
N. Nirwandy ${ }^{*}$, A. R. A. Rahman and S. M. Salleh \\ Centre of Media and Information Warfare Studies, Universiti Teknologi MARA, 40450 Shah \\ Alam, Selangor, Malaysia
}

Published online: 05 October 2017

\begin{abstract}
This conceptualization article discusses the impact of technology to society from various perspectives which relates on humanities aspect of social convention, hegemony, generation warfare and intelligence constructs. The narratives provide understandings of the current transition, emphasizing the changing need of intelligence protocols to understand the society in current technological advancement era. Intelligence output is detrimental as information is no longer secluded in this borderless communication spheres. The article narrates generation warfare intelligence in complex information system of digital asymmetrical environment in current generation warfare to digest the social implications and of technology to society and provides appropriate recommendations.
\end{abstract}

Keywords: communication; generation warfare; hegemony; intelligence; society; social convention.

Author Correspondence, e-mail: nirwandy3493@salam.uitm.edu.my doi: http://dx.doi.org/10.4314/jfas.v9i4s.31

\section{INTRODUCTION}

Numerous incidents, conflicts and terrorism acts that have been occurred in numbers of countries around the globe recently. The world become tortured by the political issues, 
dissatisfaction from enemy groups that opposed the governments of its country, issues of democracy and liberalism, international obligations, economic crisis, weapon of mass destruction, militancy and many others [1]. The asymmetrical and symmetrical enmity supports the operation of liberalism which makes the politic either is diplomacy or against domestic enemies internally [2].

These issues are having potential to be factors that would threatening national security. With the advancement of information and communication technology (ICT), people are exposed to the information regarding current situation that occurred around the globe. The information travelling to people are open-sources and those information people received are not necessarily truthful, authentic, genuine and accurate. Some information the internet are not originated from the rights purposes. Some of the information spreading throughout the internet contains manipulated information, which had ill intentions and put the harmony condition at risk. Technology advancement in this age become tools in providing unsecured information to people who lack of understanding and knowledge about the current state. The media is spoiled with daily attacks against people that need legislation play its role to ensure cyber security is taken seriously by data users [3]. People can easily be deceived by irresponsible people with dangerous purpose because people only believe on what they see without analyzing the situation from all sides. '

The current trends of warfare battle can be seen by two model, which are fourth and fifth generation warfare. Establishing common knowledge using all available networks become tools in this generation warfare reality in convincing decision makers that their strategic goals are impossible [4]. Among the core elements in this warfare context are the big data of digital asymmetrical environment (DAE).

\section{BIG DATA OF DIGITAL ASYMMETRICAL ENVIRONMENT}

Big data is a term used to define large and complex datasets that difficult to work using standard statistical software. Digital and mobile communication increasing has made the realm become more linked, networked and traceable and lead to the accessibility of large scale datasets. Social scientists could reflect some social networks to increase knowledge about the basic micro-processes and measure the tie-formation process in more detail, develop network micro-foundations from these dimensions and then study the network properties that track from it. It is uncertain whether this is conceivable for online networks in every type, 
however there are definitely more than sufficient chances to consider in order.

Such as, the blog networks micro-processes and the sharing behavior micro-processes within information sharing online communities offer themselves to such method. Survey and interview data about the actors and online community characteristics can be composed and joined with the online data [5].

Some critics have raised concerns about the fact that plentiful of the Big Data of highest interest to social scientists, predominantly communication and media scholars is the possessions of profitable bodies such as Facebook, Twitter and Google. These businesses either deny or securely control data access by researchers, directing to new digital splits worries and the classes of researcher's creation who are either rich or poor in data. It is often lacking to cultivate accessible algorithms to manage with big size of the data, in order to compute high-quality query answers from big data.

For instance, in unclean datasets are not confidence the answers to queries in those datasets. No matter how big datasets can be handle or fast query processing algorithms, the query answers computed may not be accurate and useless. Unfortunately, the data quality problems scale is extreme poorer since real-life data sources are frequently untrustworthy. Hence, the quality of big data study is as significant as methods for managing with its number which make big data as combination of quality and quantity which motivates to study the big data quality.

Five central issues of data quality should be considered which include data consistency, data accuracy, information completeness, data currency and entity resolution from theory to practice. It can be concluded that query answering in big data is completely dissimilar from querying traditional databases. It is a need to study complexity and approximation theory to describe thing than can or difficult to do for computing precise or estimated query answers. Querying big data is tough, but attainable. It demands for a new efficient query processing techniques set. Quality and quantity of big data neither works well when taken alone. To sum up, the need for revising query answering in big data cannot be excessive and the matter is a rich questions source and strength [6].

In the context of digital asymmetrical environment, it is an unconventional warfare that becoming vital as battle in physical setting has changed from the symmetrical superpower war to attacking parties that weak in technical knowledge of networking and computing system through hackers and organized crime [7]. 
This action can be state as psychological operation by using weaponization of information which targeting public opinion in order to aim a particular country. With the rise of social media, social media become the fifth estate that allows internet users to discussing and expressing their own thoughts on some occasion that differ from mainstream media. Social media become references which assumed to be more superior in performing coverage by amateur journalist than professional journalism in mainstream media [8].

Philosophical understanding on current realities motivates researcher into looking for the truth according to their id driven beliefs and values. In seeking for the realities, people seek and exploit information according their beliefs and values. Some identifications process is required to identify other component of society interactions to predict and analyze their desirable actions. Through acknowledging their exposed interactions, modifications and aligning people information seeking process will be more focus and eccentrics to their natural consonant.

Understanding the people preferences in complex information system in social media is complicated as extraction of raw data is needed from various cluster backgrounds from social media monitoring system. The data help to formulate an applicable approach to provide essential data to compute public preferences in information seeking process and taking side in their political participations from their possible means.

The expected output is an applicable conceptualized design application of the underlined efforts in digital and social media including the identification process of digital traits signatories to compute the essential variables to explore the society segment. This regulate to fabricating some digital traits signatories' procedures-to identify the cluster digital communications traits.

In $5 \mathrm{GW}$ information seeking and sharing is transpired in more niche cluster that leads to formation of complex information system due to the big data existence. Exploring the niche cluster need reliable software and conceptualizations process as this challenge is yet to be overcome solidly through any formidable approach.

With the penetration of communication, new forms of interaction are pictured with the capability of communication and computation that affected our lives. It will aim to drive technology into the background creating the information services human centric delivery [9]. Information processing capability become more integrated as computer system continue upgraded which accommodating in decision making [10]. 
People claimed that people must merely live with the reality of universal online surveillance when it applied to digital communication. Human rights and human security encountered with struggle in global aspects for the responsibility to protect people from abusive counterterrorism and global horror [11].

National security policy worked to protect from exterior aggression, preservation of law and order, enforcement of sanctity of agreement entered between different individuals for profitable transactions and providing infrastructure, education and support to the unfortunate. Military power, economic conditions, global alliances, support from international organizations and many other factors are the parameter of the concept of national security [12].

Policy can be made though it is difficult to control over information because it will cause many argument and criticism on human rights which end up with conflict and helping the worst to take advantage on this condition.

Thus, this study is conducted in identifying national security fundamentals in the big data of digital asymmetrical environment communication by providing guideline in order to understand the society. The study will also indicate how to identify the relation of society communication advancement in the big data environment of digital asymmetrical environment towards national security.

\subsection{The Relation of Society Communication and National Security}

In order to understand the relation of society communication and national security, it is understandable to view it from media perspective which explained the behavior theoretically. Critical Theory interpreted on society changing. Media Ecology theory explained on general people interaction in this age. By looking to the aspect of human needs, it is reasonable safety needs among essential needs of people based on Maslow study. These two aspects able to explained the relation between communication and security needs in the society.

\subsection{Critical Theory}

Critical Theory is an approach to initiate social change through information delivery of the forces of social dissimilarity that can inform political action intended at freedom. The philosophical and corresponding relations are focused on scientific regulation in which it cannot be conceived even if viewpoint deals with important problems [13].

Critical theory is consisting of the feelings and thoughts of a particular group at any given moment. In the context of social psychology, it keeps in explaining the psychological content typical of particular social group. Different classes of society have different relation to 
consciousness. For an instance, the simple explanation of bourgeois self-awareness does not provide the fact about this class of society. Same goes to working class consciousness does not offer a reality of their interest [14].

In Critical Theory, it is frequently described as 'post-structuralism' or 'post-modernism' within and without Cultural Studies which give strong effects in cultural studies [15]. In [16] stated that legitimation is one of the critical issues in a conflict. It can be related to conflict theory which is finding the explanation of conflict in the society. When conflict explaining the reasons, which lead to a problem, critical theory interpreting its changing of social relation

\subsection{McLuhan's Media Ecology}

Marshal McLuhan stated in Media Ecology theory that electronic media creates an instant communication, which bring us constant interaction with the world. Electronic media allows people in touch with everyone, everywhere instantaneously and builds global villages that can exchange communication with worldwide electronic community. Digital media are changing current setting as people developing ideas, beliefs, values, interest and obsessions through digital technology [12].

In Media Ecology, the attitude which attached with 'global village' had already embedded in the generation of millennia. Through observation by McLuhan, media become more natural, less artificial and more human in the patterns of communication [17].

The medium is the message. It affecting environmental as technology are additions of human physiology. People incline to manifest distinctive qualities by comparison and contrast when direct interface meet one another more than two environments. This will improve perception in the arts and general experience of people [18].

A basic idea of Media Ecology is development of communication technologies from writing to digitalization of media that affecting the users environment. It changed the world in the ways people create, information distribution and consumption and other innovation as well as development. Certain cyber-culture researchers are linking the present techno-cultural revolution of society with the innovation of printed press during 15th century. The emergence of global information networks, convergence processes, the eruption of new media and communication platforms and breaking the traditional broadcasting model created this environment. Media ecology develops a closely vital reference for understanding these developments that enhance scientific conversations about interactive digital communication by offering themes, concepts and demand [19]. 
Technology diffusing communication and information in media environment because it can be used in virtually all aspect of life which makes society behaviour is linked to technology. The thoughts are shapes and linked people by constant and direct electronic media. Cyber society relating internet or cyberspace in social life which make it called as cyber culture. As people demanded accurate and reliable information, citizen journalism spread information that did not provided in mainstream news media [20].

In the context of national security, some experts believe that new media can challenge the democracies. This is because these channels display great tools to disseminate information to public as it can share positive and negative effects on national security and military or political interest. Freedom of expression is not new but the instantly spreading information in real time is new. There are obligations on the information verification that being shared in the internet in terms of credibility of source, propaganda and counterpropaganda. The Moldavian twitter riot, the London riots, the WikiLeaks disclosures, or the Arab freedom movements are those cases related with this social communication tools to national security [21].

\subsection{Maslow's Hierarchy of Needs}

Abraham Maslow identified seven basic needs that individual feel motivated, one of them is safety and security needs which appears as the second basic needs by human. The needs for safety and security come following after psychological need have been satisfied. In this context, no harm physically, mentally or emotionally makes people feel safe. Whereas, security is satisfied there are lower of fears and anxiety in an individual [22].

In psychological level, safety needs is operated after reaching physical comfort by establishing constant stability in this world. Maslow observation offers little surprises to feel secure on safety needs of children. Many adults suffered with hardship in life that may occurred any time with political appeals for law and order. Maslow added the religious inclination on safety need due to its tendency in good way [23].

Safety needs become the following compulsive needs in order to protect individual from harm after physiological needs are satisfied. This need increase because it perceived to threaten life and survival psychologically. The desire for law and order, peace, and security in general are safety or security needs of nations. Safety needs of nations generally taken as need for economic, political and social security or stability which required nations to assisting information in order to feel safe and secure.

Assistance and support that aid the security organizations to fight law-breaking, make certain law and order and preserve common tranquility as well as display strength against external 
violence are provided by nations. Nations need also be secured of food and water security and safety from starvation and the dangerous of disease epidemics and tragedies. Lack of sufficient food and water may contribute to distressing effects, which makes them to return to the physiological needs. Improving national and individual earning will refining living conditions of nations [24].

Eventually the center of human communication is interrelated with degree of understanding the needs and public rights towards good governance. However some misinterpretations will lead to disparity of belief, values and ideas which probably will trigger protest of ruling government administration. This will be a foundation to jeopardize national security fundamentals if the agenda is associated with negative assimilation to create feat and threats to national values.

\section{THE INFLUENCE OF SOCIETY HUMAN RIGHTS AWARENESS TO NATIONAL SECURITY}

\subsection{Human Rights to World Community}

The concepts of human rights and basic human needs are closely related. Human rights is seen as the rights to the accomplishment of basic human needs which require this need to provide the foundation for human rights. Basic human needs are things that required by people in order to attain to meet its satisfaction which includes human dignity and avoidance from harm. This right form a main set of tools, legitimate claims, in the political struggles for execution of needs when it is extensively acknowledged as norm [25].

The concept of human rights lies on some things that should to be done for human lives and many of people put religion as the basis of human rights [26].

Since the end of World War II, human rights become the important measure of the political agenda and concern domestically and internationally. The trends of human rights scholarship were established after Holocaust. Human rights scholar believed in every historical era is the consequence of a dialectical connection with social reality. Besides, western people stress on individual freedom and civil and political rights. However, economic and social rights were dismissed during the Cold War era by western scholars and political leaders to against Soviet [27].

After that event, these constitutionals develop current system in order to protect human rights internationally. The ideology of Universal Declaration of Human Rights (UDHR) is based on 
equality, traditional rights and freedoms and continuing the domestic involvements of the countries of the world.

European Convention on Human Rights and the European Social Charter identified them as reaffirming their commitment to the spiritual and moral values. It is mutual tradition of people and the real substance of individual freedom, political liberty and the rule of law, doctrines which practice the foundation of all genuine democracy.

In Asia, there are no regional instrument of human rights due to different culture homogeneity in the continent and different religions and ethnic traditions of its people. However, for Arab countries, they constitute the Arab Charter of Human Rights as the instrument [28].

Furthermore, there are monitors that act as watchdog to observe the successful and failures of the rights. Among them are Amnesty International, Liberty, Human Right Watch, the American Civil Liberties Union, the Human Rights Council and the European Court of Human Rights [29].

\subsection{Human Security to Global Justice}

Human security is about the protection of freedom which consists of the human elements of security, rights and development. It concerning with human life and dignity in international, national and sub-national efforts [30].

Human Security was introduced in 1994 through Human Development Report (HDR) to extend the range of security analysis and policy from state to people security from the threats. There are two major components of human security, which is freedom of fear and freedom of war. This freedom is part of human freedom in Universal Declaration of Human Rights. Based on HDR, there are seven vital measurements of human security includes economic, health, personal, political, food, environmental and community. Threats to human security can occurred at entire levels of development which needs understanding the specific threats experienced by certain groups or people and also involvement of people in analyze process [31]. Besides, human security is a fundamental part of the mission of UNESCO which is:

"to contribute to peace and security by promoting collaboration among the nations through education, science and culture in order to further universal respect for justice, for the rule of law and for human rights and fundamental freedoms which are affirmed for the peoples of the world, without distinction of race, sex, language or religion" [32].

Human security needs all judgments about important means took under public scrutiny and regulation which would be global justice. However, the "democratic control" in a structure ruled by private organizations is hard to obtain [11]. 


\subsection{Human Development Index}

The Human Development Index (HDI) is three basic levels of human development that summarize measurement to evaluating long-term development. It includes a healthy life, access to information and a standard of living. Life expectancy is measuring the healthy life. Average number of years of education among the adult people will measure the knowledge level. The access to learning and knowledge by expected years of schooling for children of school-entry age can assume to receive dominant patterns of age-specific enrolment. Gross National Income (GNI) per capita measured standard of living.

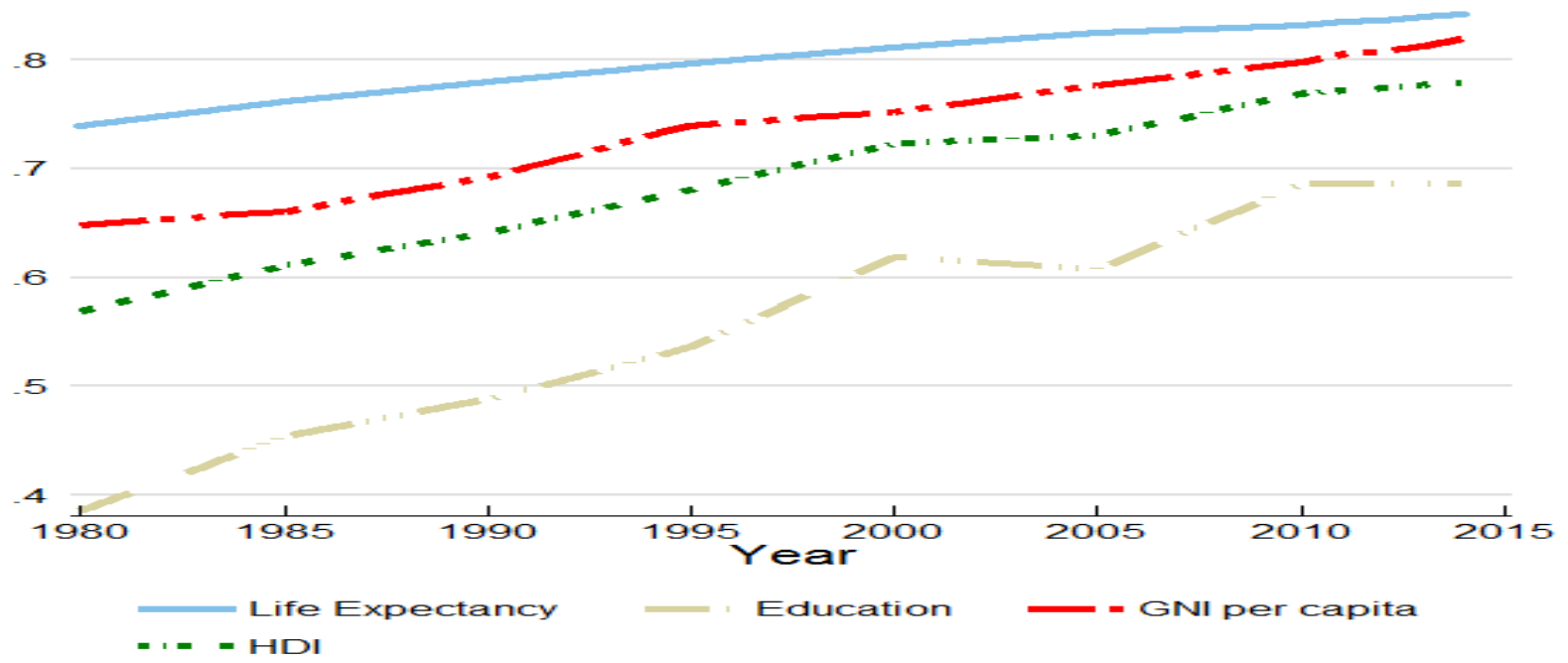

Fig.1. Trends in Malaysia's HDI component indexes 1980-2014

Life expectancy at birth increased by 6.6 years, mean years of schooling increased by 6.0 years and expected years of schooling increased by 3.7 years between 1980 and 2014 in Malaysia. GNI per capita of Malaysia improved about 211.2\% between 1980 and 2014 [33]. In 2015, Human Development Report by UNDP stated that Malaysia was listed among high human development country and ranked at 62 of 188 countries in the world. The Human Development Index (HDI) value in 2014 is 0.779 , years for life expectancy at birth is 74.7, expected years of schooling is 12.7 , mean years of schooling is 10 and GNI is 22,762 . The highest country ranked in HDI belongs to Norway, followed by Australia and Switzerland. Meanwhile, the lowest country in HDI is Nigeria [34].

\section{ANALYZING SOCIAL MEDIA IN DIGITAL ETHNOGRAPHY}

In order to makes sure public discourse particularly in social media does not lead to potential threat to national security, constant evaluation or analysis have to be conducted regularly. In the big data of digital asymmetrical environment finding discourse or foundation of revolution 
element is hard without systematic structure data analysis procedures.

Digital ethnography is vital in assuring the analytical process is using proper method to capture the needed data. In [35] stated there are six ways in order to conduct a study using digital ethnography method. The six techniques are by studying the viral contents, the digital technologies, the digital technologists, a single field contention, a series of fields of contention and also the protest temporalities.

Avatar and Sentiment Analysis are also among other method in conducting digital ethnography study. Below are the explanation regarding the methods used by these authors.

\subsection{Viral Contents}

'Media epidemiography' blends the terms 'epidemiology' and 'ethnography' as an incitement to deliberate about by what means people could study ethnographically the media epidemiology of popular demonstrations that go viral and transform into new social movements [36]. In the new age of reality, people are co-defining interesting story through the increased ability of people to select which digital contents they prefer to share using their own personal network.

The convergence cultures bring difficult challenges to ethnographers which oblige new conceptual approaches. The term media epidemiography signify the technique in epidemiology. Epidemiology of representations with the ethnography of digital media. It is done by tracking on two things which are distribution of digital contents such as viral campaign and given population within a specific demographic such as law student in Spain.

Interviews with people involve and topic in Twitter that become trending are among digital forensics techniques that media epidemiographers need to improve in order to examine digital contents.

\subsection{Digital Technologies}

Ethnographers need to follow at least one or more digital technologies as they pass through separate social settings. It can be done by ensemble various kinds of media which make them appear mixture of digital media such as combining radio, printed media and television. This is also known as media ensemble

\subsection{Digital Technologists}


Digital ethnographer can also be preferred to used digital technologist rather than technologies such as by using those people who highly involved in exploring the parameters and prospects of new digital technology like online journalists, bloggers, vloggers and others.

Digital ethnographer need to follow them frequently to engage them with real time participation by collecting information through interviews, web archives, social media, field notes and others. Information posted on these technologies are being scattered through Twitter and others and reach research participants.

Through this way, the work of ethnographer, activists and other actors will meet together as an issue remain to disseminate.

\subsection{A Single Field Contention}

Field here represent the concept of social world. Field of contention also known as movement field in which field agents including technologists stressed on a minor set of specific issues and rewards through digital media. There are many institutionalized fields such as art, sociology or journalism studied make the movement-field in the digital age become dynamic. Through that, many aspects can be highly derived from participation regardless of past qualifications or social identity.

\subsection{A Series of Fields of Contention}

Digital ethnographer can also run several fields to see the relationship between other single fields in pursuit of the same issues. Technologists have freedom to explore and experience a distinctive boundaries and potentials of mixing technology with other means.

\subsection{The Protest Temporalities}

Digital ethnographers have another technique which is by approaching social world to see the root of the process of an issue in non-linear time. Events, routines and trends act as three different forms of temporality with their own unique paths. Some events sometimes will have a direct impact on the routine of a social world's web. Trends of interest also to movement-field participants themselves beside of ethnographers because some of it may turns into direct action.

\subsection{Avatar}

Avatar is defined as any form of representation of an individual. It may come in the form of 
name, voice, photo, and others which may also not appear like user. It may present as a form of realism like human user and behavioural realism which influence on responds to the avatar by other people. It assisted as visual in the interaction in digital environment which relied on textual communication.

It has several options for individual customization of avatars which allowing users to change physical features and not only build representation of themselves. Avatars can interact as the user, build practices and develop characteristics in the form of virtual human [7].

People nowadays develop friendships through online, which make them create impressions based on representation of a person. Some are easily inferred from avatar that communicates more accurately on a person personality. There has been suggested in a study that a person in online are more informative because they provide more information through personal social networking profile than individual in person.

The result from the study stated that avatars act as virtual proxies in infer information of an individual personality accurately. It is important impact in friendship through impressions that people make online [8].

There are different ways of communication by using avatar which allows users to have control over sits designated avatars. It is available on the internet which makes it suitable to study on user behaviour. It well suited for presentation of multimedia content and systematic collecting of responses by users. It includes study on the application, preferences of interaction by group of users and also on personality traits that influence the behaviour.

A study was conducted by using movie as agents interacting with each other. Users reacted to the movie clips by giving avatar feedback. Through that, users are able to provide information from the access on users' feeling about behaviour of avatar. This method can be used in order to study on the effectiveness of avatar communication [37].

\subsection{Sentiment Analysis}

Sentiment analysis also known as opinion mining is the study that examines opinion of people, sentiments, evaluations, judgments, attitudes and feelings towards entities that signifies a large problem space. Sentiment analysis is generally concentrated on opinions that express or involve positive or negative sentiments. It is recently being at the center of the social media 
research regularly to study explanation of metaphors, sentiments adjectives, prejudice, standpoints and effects [38].

Sentiment analysis in its pure method does not challenge to critic fairness or the strong point of the factual base. However, it rather calculates the intensity and polarization of the feelings conveyed towards the area of concern. There are some tactics to estimate sentiment analysis score. There are numerous different models used, which is from statistical to language processing along with the sensitivity and granularity [39].

In this field, researchers have also discovered techniques to avoid annotation by utilizing the resources. Labelling is a common technique, but there are also several other main techniques existed such as collecting sentiment summaries as one-sentence summaries and also gathering subjective against non-subjective texts on the same topic. Researchers also can search current and latest queries to search engines in order to find sentiment sentences. Emoticons and images of logo portrayed by people are also the techniques that derived from the labelling effect. As for negative opinions, it can be collected by observing from post in newsgroup that has negative sentiment being cited by people such as uproar and capital letter text [34].

Algorithm for sentiment analysis involve information extraction from sources includes detecting sentiments of any individual from the text is writes in digital format. Classification algorithms are widely used in sentiment classification. It is a phase in sentiment analysis that defines process by predicting qualitative response through its polarity. There are four major steps which are text extraction which involve with extracting words from text that impact the effect of the results, text refinement which is refine text in form of relevant phrase, text classification by categorize into positive and negative and score aggregation which is gather total scores to create the total sentiment score [10].

\section{KEYWORDS IN DIGITAL ETHNOGRAPHY}

There are two approached in automatic keywords, which is keyword assignment and keyword extraction. Feature selection for keyword extraction can be classified in two categories, which are based on phraseness and informativeness [15].

Keyword research is the practice of searching at what users are looking for and how people 
explore it on the internet. It assists us in understanding of the sorts of things people are trying to discover and also words people used which can drive further than basic information. There are several concepts about keyword which includes vertical keyword research, lateral keyword research, digging, keyword popularity, keyword competition and others.

Different tasks require different kind of tools in generating better outcome. In [15] provide explanation in understanding of keyword extraction techniques. Researchers stated that there are three approaches in determining potential keywords which are statistical approach, supervised approach and unsupervised approach. First, statistical approach can be done through discrimination value analysis, draw index terms from text, tendency of words attracts each other and build a cluster, the spatial use of words and generalization of the level statistical analysis of quantum disorder systems. Second, Supervised approach may extract keywords by using genetic algorithm and a set of parametric heuristic procedures.

Algorithm represents as sequence of words based on sequential patterns related on a document. Third, unsupervised approach measure the information content of words by using heuristics such as italic, presence in header and acronyms.

Keyword extraction is a work that identifies automatically terms which describe the best of the subject of documents. Words that arisen in the document are examined in order to detect the most representative word. There are several approaches such as simple statistic approaches, machine learning approaches and linguistic approaches. Simple statistic approaches using simple method that the training data are not required.

There are four techniques can be used in order to develop keywords in social media:

- Gather keyword volume: Many listening tools of social media provide scrape keyword volume. There are two benefits which are social media is real time and how people using keywords in social media.

- Keywords in context: Social media keyword research allow user to read how keyword are used. Semantic keyword research help people to determine the mini of people who search for a particular phrase.

- Scrape social for content for the best way to target user and show things that users want. 
- Find for curators: This is to drive traffic so that it will go outreach that helpful to assist in discovering people that mention or talk about the topic. It allows people to evaluate identified users' followers in order to aim content that people will interested and also determining people that presently speaking about it.

Conducting keyword research for social media allows researcher to determine the desires and requirements of social community by following popular and trending topics on Twitter and other social network, determining search frequency, recognizing request for keywords and many more [40].

\section{THE FRAMEWORK OF NATIONAL SECURITY POLICY}

\section{THROUGHGOVERNMENT COMMUNICATION STRATEGY}

Globally countries around the world including Malaysia have to adopt structure data extraction and analytical mechanism. This expertise enhance national security fundamentals through evaluating certain threat to the national interest. Internet of Things, IOT in the big data of digital asymmetrical environment are making cognitive restoration more complex .China, govern it communication through internet as it developed a gradually divisive power within China in recently. There are more than 111 million internet users in China with 40,000 internet police required to observing the interchange of information over networks in China. Although this is challenge law, with the progressively technological accessibility and internet communication have assisted to the spread of information and conflict throughout China [41].

In contrast, there is no censorship of social media because freedom of expression on the internet is usually accepted in Russia. The practice of Distributed Denial of Service (DDoS) attack against media channel threatening the government is common. If it is necessary, the legal authority would entirely close down the website. Russia prevents overt approaches of controlling cyberspace. However, internet is also an important sector for some Russian leadership and security agencies as more of a threat than an enabler [42].

As for United State government, the Department of Defence (DoD) rely on the utility and information gathering of cyberspace. DoD controls over 15,000 networks and seven million computing devices across hundreds of installations in numbers of countries around the world. DoD utilize cyberspace to support its military, intelligence and business procedures. This is 
comprising of the movement of personnel, material, facility and regulating of the full scale of military operations [43].

\section{CONCLUSION}

Advancement of technology has taken place in today's communication world, yet it has also changed the pattern of how people interact with one and another. Digitalization communication allows people from various places to engage in communicating with people from different places, nevertheless the upgrading of communication platform and method might affect state's national security. With the existence of the Internet, nowadays, everything will be reported in the social media and the data is kept as a big data. Governments need to know on how to control the usage of social media in exposing opinions as well as information.

Apart from that, the Internet is useful despite of the excessive information exposed in the cyberspace, but the Internet can become a great platform for the government and organizations to keep updated with the current trends of today's generation. This is the place where intelligence agencies can identify what is in the mind of the society. The existence of Internet and social media do not necessarily only bring negative impacts. However, it might be a good platform for the country to improvise their strategy on how to win the mind and heart of the society. Besides, it can be used for gathering and collecting information in which it might help to secure the peace and harmony of the country. Therefore, the exposure to the term big data is not new to current generation, but the way of how it is going to be utilized, should be monitored as for in our local context to avoid on any controversial issues that can threaten the national security.

\section{REFERENCES}

[1] Ramcharan B. G. Contemporary human rights ideas. New York: Routledge, 2008

[2] Thorup M. Critiques of liberal globalism. Defence of Enmity, 2006, pp. 3-4

[3] Woodward A, Williams PA. An uncomfortable change: Shifting perceptions to establish pragmatic cyber security. In H. Unger, P. Meesad, \& S. Boonkrong (Eds.), Recent advances in information and communication technology. Cham: Springer, 2015, pp. 1-8

[4] Barnett D. The fallacies of fourth and fifth generation warfare. Small Wars Journal, 2010, 13(9):1-3 
[5] Snijders C, Matzat U, Reips U D. " Big Data": big gaps of knowledge in the field of internet science. International Journal of Internet Science, 2012, 7(1):1-5

[6] Fan W, Huai J P. Querying big data: bridging theory and practice. Journal of Computer Science and Technology, 2014, 29(5):849-869

[7] Fox J, Bailenson J N, Tricase L. The embodiment of sexualized virtual selves: The Proteus effect and experiences of self-objectification via avatars. Computers in Human Behavior, 2013, 29(3):930-938

[8] Fong K, Mar R A. What does my avatar say about me? Inferring personality from avatars. Personality and Social Psychology Bulletin, 2015, 41(2):237-249

[9] Choi H, Varian H. Predicting the present with Google Trends. Economic Record, 2012, 88(s1):2-9

[10] Aher S B, Lobo L M. Comparative study of classification algorithms. International Journal of Information Technology, 2012, 5(2):239-243

[11] Holmstrom N. Security and global justice. Logos, 2003, 3:1-12

[12] McLuhan M. Media ecology. In E. Griffin (Ed.), A first look at communication theory. New York: McGraw Hill, 2012, pp. 321-327

[13] Rush F. Conceptual foundations of early critical theory. In F. L. Rush (Ed.), The Cambridge to critical theory. England: Cambridge University Press, 2004, pp. 6-39

[14] Horkheimer M. Traditional and critical theory. In C. Calhoum (Ed.), Classical sociological theory. Oxford: Blackwell, 2001, pp. 1-11

[15] Siddiqi S, Sharan A. Keyword and keyphrase extraction techniques: A literature review. International Journal of Computer Applications, 2015, 109(2):18-22

[16] Coser L, Dahrendorf R, Collins R. Chapter 7: Conflict and critical theories. https://www.corwin.com/sites/default/files/upm-binaries/13636_Chapter7.pdf

[17] Levinson P. McLuhan and media ecology. In Media Ecology Association, 2000, pp. 17-22

[18] McLuhan E. Marshall McLuhan's theory of communication: The Yegg 1. Global Media Journal, 2008, 1(1):25-43

[19] Scolari C. Media ecology. Map of a theoretical niche. Quaderns del CAC, 2010, 34(1):17-25

[20] Djajalie K. Citizen journalist: A case study on using blogs for self-promotion. Singapore: Solstice Publishing, 2010 
[21] Meghesan K, Mihalache V. The national security-media power linkage: A theoretical framework. 2012 , http://ndc.gov.bd/lib_mgmt/webroot/earticle/1610/National_Security_Media_Power_Linkage. pdf

[22] Martin D. J., Loomis K. S. Building teachers: A constructivist approach to introducing education. Boston: Cengage Learning, 2013

[23] Griffin E. A., Crossman J., Bordia S., Mills C., Maras S., Pearse G., Kelly P., Shanahan D. A first look at communication theory. Boston: McGraw-Hill Education, 2014

[24] Yawson D O, Armah F A, Pappoe A N. Enabling sustainability: Hierarchical need-based framework for promoting sustainable data infrastructure in developing countries. Sustainability, 2009, 1(4):946-959

[25] Gasper D. Needs and human rights. In R. K. Smith, \& C. V. Anker (Eds.), The essentials of human rights. London: Hodder Arnold, 2005, pp. 1-4

[26] Perry M. Michael Perry and the religious cosmology: Foundations and critiques of human rights. In A. Kohen (Ed.), In defense of human rights: A non-religious grounding in a pluralistic world. London: Routledge, 2007, pp. 13-15

[27] Pollis A. A New universalism. In A. Pollis, \& P. Schwab (Eds.), Human rights: New perspectives, new realities. New Delhi: Lynne Rienner Publishers, 2002, pp. 9-30

[28] Tomuschat C. Human rights: Between idealism and realism. New York: Oxford University Press, 2003

[29] Whittaker D. J. Counter-terrorism and human rights. Harlow: Pearson Education Limited, 2009

[30] Appiah M, Jackson E. Corporate social responsibility and human security in fragile states. The Hague: The Hague Institute for Global Justice, 2015

[31] Gomez O A, Gasper D. Human security: A thematic guidance note for regional and national human development report teams. New York: United Nations Development Programme Human Development Report Office, 2013

[32] United Nations Educational, Scientific and Cultural Organization (UNESCO). Human security: Approaches and challenges. Paris: United Nations Educational, 2008

[33] United Nations Development Programme (UNDP). Human development report. New York: UNDP, 2015

[34] Pang B, Lee L. Opinion mining and sentiment analysis. Foundations and Trends ${ }^{\circledR}$ in Information Retrieval, 2008, 2(1-2):1-35 
[35] Pink S., Horst H., Postill J., Hjorth L., Lewis T., Tacchi J. Digital ethnography: Principles and practices. London: SAGE Publishing, 2016

[36] Postill J. Democracy in an age of viral reality: A media epidemiography of Spain's indignados movement. Ethnography, 2014, 15(1):51-69

[37] Krenn B, Gstrein E, Neumayr B, Grice M. What can we learn from users of avatars in net environments. In AAMAS Workshop “Embodied Conversational Agentslet's Specify and Evaluate Them, 2002, pp. 1-7

[38] Liu B. Sentiment analysis and opinion mining. Toronto: Morgan and Claypool Publishers, 2012

[39] Kagan V., Rossini E., Sapounas D. Sentiment analysis for PTSD signals. New York: Springer Science and Business Media, 2013

[40] WordStream. The experts' guide to keyword research for social media. Massachusetts: WordStream, 2013

[41] Bolt P J, Gray A K. China's national security strategy. Colorado: U.S. Air Force Academy, 2007

[42] Giles K. Russian cyber security: Concepts and current activity. London: Chatham House, 2012

[43] US Department of Defense (DoD). The DoD cyber strategy. Virginia: DoD, 2015

\section{How to cite this article:}

Nirwandy N, Rahman ARA, Salleh SM. Identifying national security fundamentals in the big data of digital asymmetrical environment communication. J. Fundam. Appl. Sci., 2017, 9(4S), 543-562. 